\title{
Erosion Testing of Coatings for V-22 Aircraft Applications
}

\author{
G. Y. Richardson and C. S. Lei \\ Naval Air Station, Patuxent River, Maryland, USA \\ W. Tabakoff \\ Department of AE\&EM, University of Cincinnati, Cincinnati, Ohio, USA
}

High-velocity $(183 \mathrm{~m} / \mathrm{sec})$ sand erosion tests in a wind tunnel were conducted to evaluate developmental coatings from three separate companies under funding by the Navy's phase I small business innovative research program. The purpose of the coatings was to address a particular problem the V-22 tilt-rotor aircraft (Osprey) was having with regard to ingestion of sand particles by a titanium impeller that was associated with the aircraft's environmental control system. The three coatings that were deposited on titanium substrates and erosion-tested included (1) $\mathrm{Si}_{\mathrm{x}} \mathrm{C}_{\mathrm{y}} / \mathrm{DLC}$ multilayers deposited by chemical vapor deposition (CVD); (2) $\mathrm{WC} / \mathrm{TaC} / \mathrm{TiC}$ processed by electrospark deposition; and (3) polymer ceramic mixtures applied by means of an aqueous synthesis. The erosion test results are presented; they provided the basis for assessing the suitability of some of these coatings for the intended application.

Keywords chemical vapor deposition, coatings, diamond-like carbon, electrospark deposition, erosion

The Navy's V-22 tilt-rotor aircraft (Osprey) uses a shaftdriven compressor (SDC) to supply compressed air to the environmental control system, the onboard oxygen-generation system, and the wings' deicing system. This compressor requires a high-speed $(100,000 \mathrm{rpm})$ impeller for air intake and is equipped with a particle separator to prevent abrasive particles contained in the airstream from contacting the titanium (Ti) impeller. Lowaltitude operations in helicopter mode over sandy or in dusty

Received 1 March 2002; accepted 19 November 2002.

The authors gratefully acknowledge the support of the NAVAIR Science \& Technology Office, the V-22 program office, and the Office of Naval Research for supporting this effort.

Address correspondence to W. Tabakoff, Department of AE\&EM, University of Cincinnati, Cincinnati, OH 45221, USA. environments have resulted in an overtaxed particle separator and rapid wear of the impeller fins, causing significant performance reductions and in some cases catastrophic failure of the impellers. This article reports the results of a small business innovative research (SBIR) program solicited by the U.S. Navy (NAVAIR, Aerospace Materials Division, Patuxent River, MD) and awarded to three companies with unique coatings or surfacetreatment approaches.

The three coatings that were deposited were (1) (SiC/DLC) multilayers deposited by (CVD); (2) (WC/TaC/TiC) processed by electrospark deposition; and (3) polymer ceramic mixtures applied by means of aqueous synthesis. Each of these coating systems was optimized and applied to the Ti-based (Ti-6A1-4V) substrates, and some of the properties that were relevant to protection against erosion were measured, including erosion tests in a wind tunnel (Tabakoff, 1995). The erosion-resistant coatings must possess certain attributes in order to protect the substrate, and the process of their deposition should be benign enough to avoid degrading the substrate materials. Some of these attributes include strong adhesion to the substrate, a hard and aerodynamically smooth coating, high fracture toughness, low internal state of tensile residual stress, low-temperature processing to maintain substrate metallurgy, conformal coating methods, and a low erosion rate so as to significantly extend the product's life cycle. The results obtained from the wind-tunnel tests for each of the coating systems are presented in this article, and those results were then used to assess the products' potential for protection against erosion of Ti-based substrate materials. The initial findings were then used to downselect promising coating systems for further development in the Phase II SBIR program.

\section{EXPERIMENTAL PROCEDURES AND RESULTS}

\section{$\mathrm{Si}_{\mathrm{x}} \mathrm{C}_{\mathrm{y}} / \mathrm{DLC}$ Multilayers Deposited by CVD}

A diamond-like carbon (DLC) coating was deposited on Ti$6 \mathrm{~A} 1-4 \mathrm{~V}$ coupons $25.4 \mathrm{~mm} \times 25.4 \mathrm{~mm}$ using a low-temperature 
TABLE 1

Erosion Test Results on a Nano-Laminated $\mathrm{Si}_{\mathrm{x}} \mathrm{C}_{\mathrm{y}} / \mathrm{DLC}$ Coating Structure Using Alumina Particles $(9.5 \mu \mathrm{m})$ at $183 \mathrm{~m} / \mathrm{sec}$

\begin{tabular}{lcc}
\hline Angle of impact & Mass loading (g) & Erosion rate $(\mathrm{mg} / \mathrm{g})$ \\
\hline $90^{\circ}$ & 5 & 0.092 \\
$90^{\circ}$ & 5 & 0.074 \\
$90^{\circ}$ & 20 & 0.05 \\
$90^{\circ}$ & 30 & 0.03 \\
$90^{\circ}$ & 100 & 0.03 \\
& 160 (total) & .0552 \\
$30^{\circ}$ & 10 & 0.270 \\
$30^{\circ}$ & 50 & 0.60 \\
$30^{\circ}$ & 20 & 1.11 \\
$30^{\circ}$ & 20 & 1.4 \\
& 100 (total) & 0.845 \\
\hline
\end{tabular}

$\left(<150^{\circ} \mathrm{C}\right) \mathrm{CVD}$ process. A multilayered coating $25 \mu \mathrm{m}$ thick and consisting of 25 alternate layers of amorphous $\mathrm{Si}_{\mathrm{x}} \mathrm{C}_{\mathrm{y}}(0.25$ $\mu \mathrm{m})$ and DLC $(0.75 \mu \mathrm{m})$ were deposited on the substrates. The advantages of the multilayered concept are that they provide high fracture toughness, low internal stresses, and the ability to control both the total stress in the coating and a (positive) compressive stress at the coating surface. Changes in the thickness of the individual layers and in the numbers of alternating layers were made to study the effects on selected properties so as to obtain an optimized coating system.

Coated samples were characterized by adhesion tests using the standards of the American Society for Testing and Materials (ASTM D3359-97). In this test, a scratch was made and a 3M tape was bonded to the coated surface and peeled off. This test indicated no removal of the coating by the tape, which was an indication of excellent adhesion. Erosion tests were initially conducted at University of Dayton, where they regularly perform dust erosion tests for aircraft cockpit canopies and monitor the changes in transmission as a result of scratching the window. These conditions were too mild to simulate the level of erosion that was typical for the Ti impeller. Consequently, erosion tests were done in a wind-tunnel facility at the University of Cincinnati, using Arizona dust with silica particles between 10 and $100 \mu \mathrm{m}$ and alumina particles of $9.5 \mu \mathrm{m}$ at particle velocities of $183 \mathrm{~m} / \mathrm{sec}$. The initial set of samples with just the DLC coating did not survive, but the multilayered (nanolaminated) coating, consisting of $\mathrm{Si}_{\mathrm{x}} \mathrm{C}_{\mathrm{y}}$ and DLC, displayed very good erosion

TABLE 2

Erosion Test Results on a Nano-Laminated $\mathrm{Si}_{\mathrm{x}} \mathrm{C}_{\mathrm{y}} / \mathrm{DLC}$ Coating Structure Using Silica Particles (100-200 $\mu \mathrm{m})$ at $183 \mathrm{~m} / \mathrm{sec}$

\begin{tabular}{lcc}
\hline Angle of impact & Mass loading $(\mathrm{g})$ & Erosion rate $(\mathrm{mg} / \mathrm{g})$ \\
\hline $90^{\circ}$ & 100 & 1.76 \\
$90^{\circ}$ & 100 & 1.10 \\
& 200 (total) & 1.43 \\
\hline
\end{tabular}

TABLE 3

Wear Volume for Various Samples of $\mathrm{Si}_{\mathrm{x}} \mathrm{C}_{\mathrm{y}} / \mathrm{DLC}$

\begin{tabular}{lcc}
\hline Sample $^{a}$ & $\begin{array}{c}\text { Wear volume }\left(\mathrm{mm}^{3}\right) \\
\text { at a load of } 10 \mathrm{~N}\end{array}$ & $\begin{array}{c}\text { Wear volume }\left(\mathrm{mm}^{3}\right) \\
\text { at a load of } 15.68 \mathrm{~N}\end{array}$ \\
\hline A & NMW & 0.02058 \\
B & NMW & 0.02252 \\
C & NMW & 0.01355 \\
D & 4.1134 & - \\
E & 6.8606 & - \\
\hline
\end{tabular}

${ }^{a}$ The samples tested were Sample A: $2-\mu \mathrm{m}$-thick ultraC diamondhard carbon coating; Sample B: $15-\mu \mathrm{m}$-thick $\mathrm{SiC}+2-\mu \mathrm{m}$-thick ultraC diamond-hard carbon coating; Sample C: layered structure (SiC and ultraC) totaling six layers; sample D: $15-\mu$ m-thick Sic; Sample E: Bare Ti alloy.

NMW, no measurable wear.

resistance. A summary of the test results is shown in Tables 1 and 2.

Friction and wear tests were also conducted to gauge the performance of these coatings on Ti-based substrates. Pin-on-disk tests were performed in which the Ti-based disk was coated with various coatings, and the pin was either an alumina or a silicon nitride ball. The test on alumina was done at a load of $10 \mathrm{~N}$, and on silicon nitride, a load of $15.68 \mathrm{~N}$ was used. Tests were done at $71 \mathrm{rpm}$ and a linear speed of $10 \mathrm{~cm} / \mathrm{sec}$. The results of the wear tests are shown in Table 3. It is apparent that the layered coating, designation $\mathrm{C}$, displayed superior wear performance, which is consistent with the results of the erosion test. The hardness and elastic modulus of the layered coatings was reported to be 25.8 GPa and $206 \mathrm{GPa}$, respectively. In addition, the CVD multilayer coating process demonstrated excellent ability to coat the complex shapes of an actual impeller, as shown in Figure 1. It should

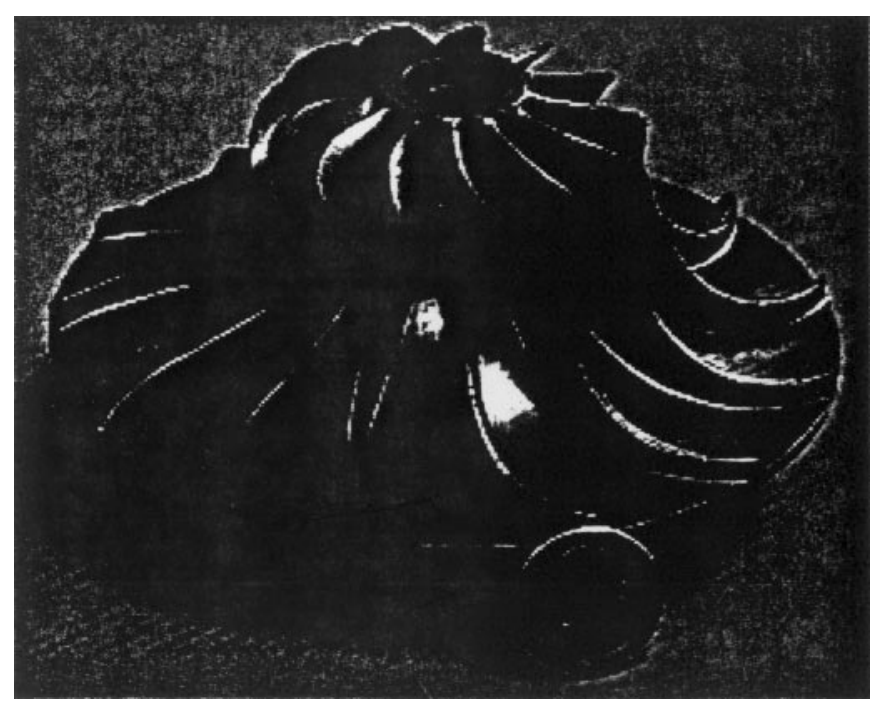

FIGURE 1

Photograph of a scrap SDC titanium alloy impeller coated with Surmet's hard carbon erosion-resistant coating. 


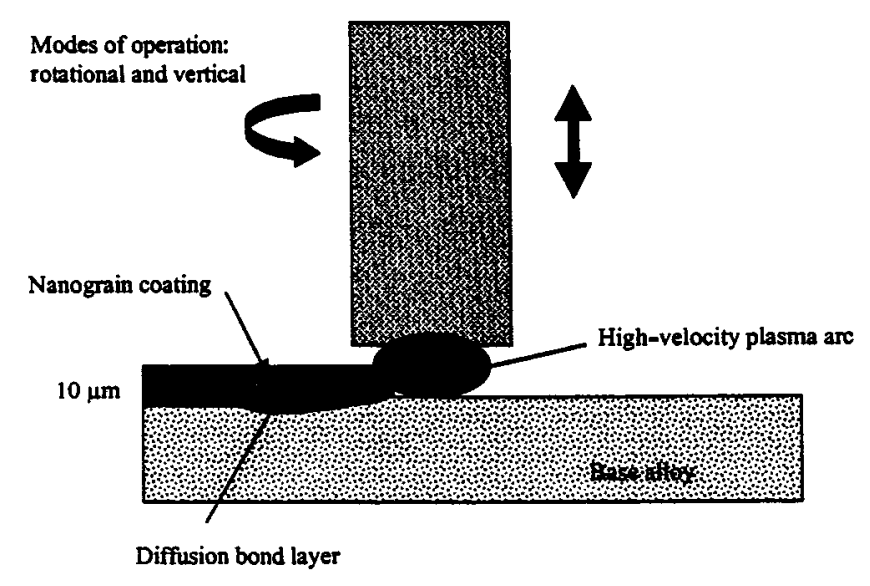

FIGURE 2

Schematic of the electrospark alloying process showing the electrode transfer into the bulk alloy.

be noted that this impeller had seen time in a compressor prior to coating, as is evidenced by the rounded impeller blade tips.

\section{WC/TaC/TiC Processed by Electrospark Deposition}

In this approach, (WC-TaC-Co) and (WC-TiC-Co) coatings were deposited on Ti-based substrates using electrospark alloying shown in Figure 2. The process used an electrode of the coating material that is deposited on the substrate by means of a microwelding process as the electrode is rastered over the substrate. Initial tests utilized coatings of WC-TaC-Co; WC-TiC$\mathrm{Co} ; \mathrm{Cr}_{3} \mathrm{C}_{2}-\mathrm{Ni}$; TiC-Ni-Mo; $\mathrm{TiB}_{2}$; and the baseline Ti alloy. An in-house erosion test was used to assess the initial performance of these coatings. These tests were done using $50-\mu \mathrm{m}$ alumina particulate at $152.4 \mathrm{~m} / \mathrm{sec} ; 30$-degree and 90 -degree incident angles; and a particle loading of $12 \mathrm{~g} / \mathrm{min}$. The tests were run for the relatively short time of $1 \mathrm{~min}$. The results of these tests are shown in Figures 3 and 4. They show higher erosion rates for tests done at a 30-degree angle than at a 90-degree angle. None of the coatings breached, and two of the best-performing coatings, based on WC-TaC-Co and WC-TiC-Co, were further evaluated for 3-min durations with good results.

Additional independent erosion testing was conducted in the wind tunnel at the University of Cincinnati. These tests included WC-Tac-Co and WC-TiC-Co coatings $50 \mu \mathrm{m}$ in thickness. This first set of coatings showed excessive wear in tests done at the University of Cincinnati. Similar tests also performed there, on another set of reengineered coatings, showed better erosion behavior, but it was not as good as that shown by the other coating methods. The coating process was also demonstrated on an impeller; however, feedback from the manufacturer of the impeller indicated that the surface roughness resulting from the ESD coating process was not desirable for this high-speed aerodynamic component.

\section{Polymer-Ceramic Coatings Applied via an Aqueous Synthesis Route}

The coating concept consisted of a mixutre of nanoscale ceramic particles (e.g., silicon nitride, titanium di-boride, etc.) in a specially formulated polymer matrix to protect the Ti-based materials from erosive wear. The basis of the approach was that a hard ceramic coating experiences harder wear at a 90-degree impingement angle and a soft metallic coating experiences harder wear at low impingement angles (e.g., 30 degrees). Therefore, a mixture of a soft polymer matrix containing hard ceramic particles in a composite coating may offer superior protection for application to impellers.

$152.4 \mathrm{~m} / \mathrm{sec}, 90^{\circ}$ angle, $12 \mathrm{~g} / \mathrm{min}, 50 \mu \mathrm{m} \mathrm{Al} \mathrm{O}_{3}, 6.35 \mathrm{~mm}$-dlameter nozzle

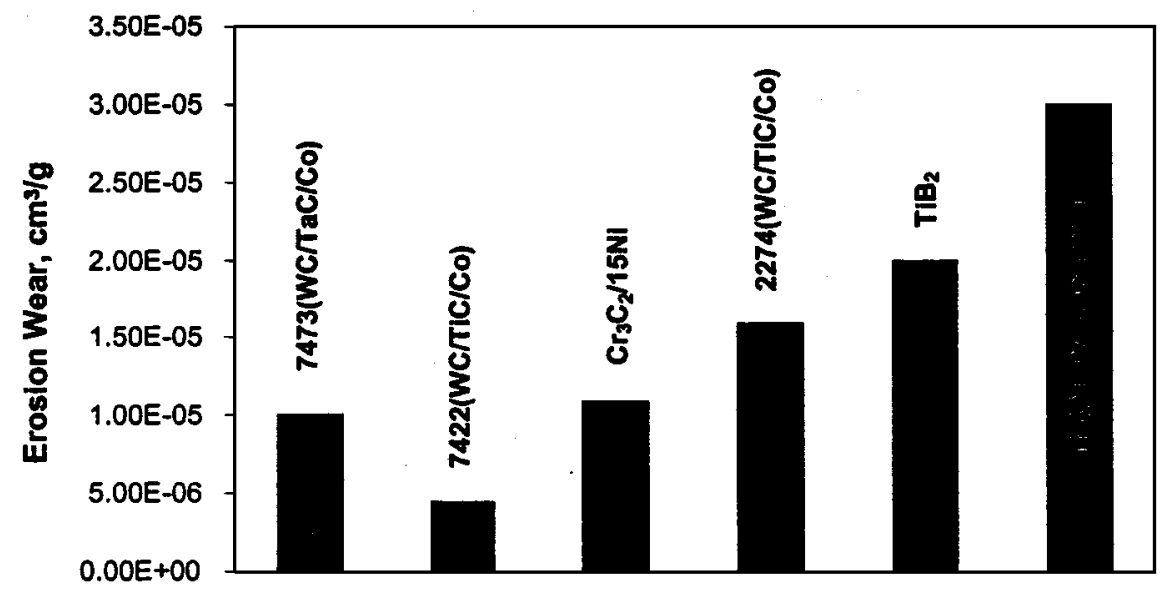

FIGURE 3

Results of the 1-min erosion test at a 90-degree impact angle. 
$152.4 \mathrm{~m} / \mathrm{sec}, 30^{\circ}$ angle, $12 \mathrm{~g} / \mathrm{min}, 50 \mu \mathrm{m} \mathrm{Al}_{2} \mathrm{O}_{3}, 6.35 \mathrm{~mm}$-diameter nozzle

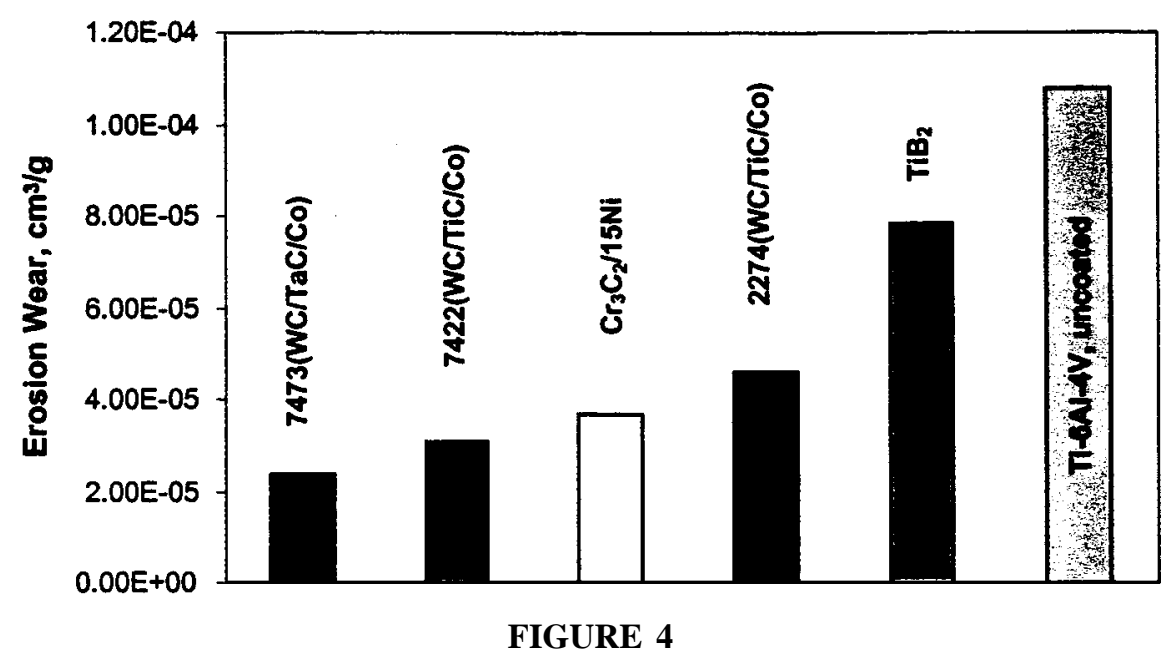

Results of the 1-min erosion test at a 30-degree impact angle.

Initial tests were performed on a variety of coating systems with various combinations of ceramic powder and polymer so as to determine the relative erosion rates, the adhesion of coatings to the substrate, and the effects of the coating processing on the fatigue behavior of the Ti-based substrate material. Based on these results, a number of promising coatings were tried in the Phase-I SBIR program. The coatings designated as (ECN) consist of urethane-based polymer matrices; (MCS) refers to sol-gel-derived polymer matrices;

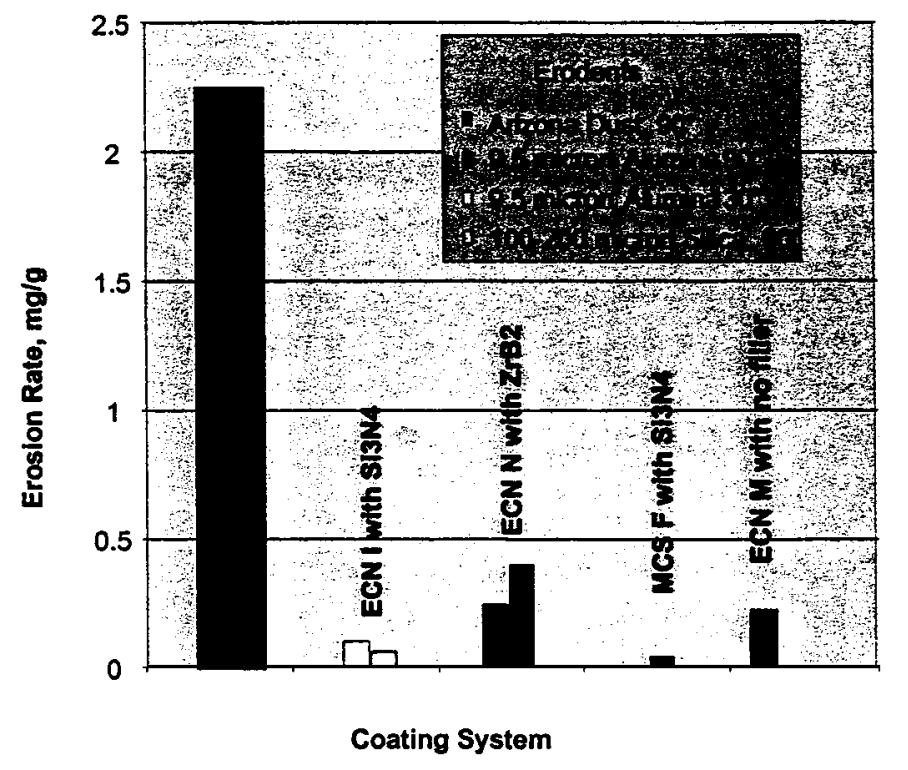

FIGURE 5

Erosion rates measured at University of Cincinnati in tests at $183 \mathrm{~m} / \mathrm{sec}(600 \mathrm{feet} / \mathrm{sec})$. and $(\mathrm{GN}(\mathrm{H}, \mathrm{Y})$ refers to epoxy-based polymer matrices. Further designations such as ECN-(A,H,I) refer to the specific tailoring of the polymers to optimize their thermoelastic response. Figure 5 shows the results of in-house erosion tests of uncoated and coated samples exposed to Arizona dust, alumina, and silica particles. Coatings with series MCS and ECN appear to be promising and show particularly low erosion rates. Figure 6 provides a summary of the adhesion test results on these coatings. Some of the coatings such as GNH C show particularly good adhesion, which was enhanced by adhesion promoters.

Promising coatings were further optimized for the type and the amount of the filler and their influence on the erosion rate. The erosion behavior of the coated substrates was compared with the erosion behavior of the uncoated base metal with a WC-Co

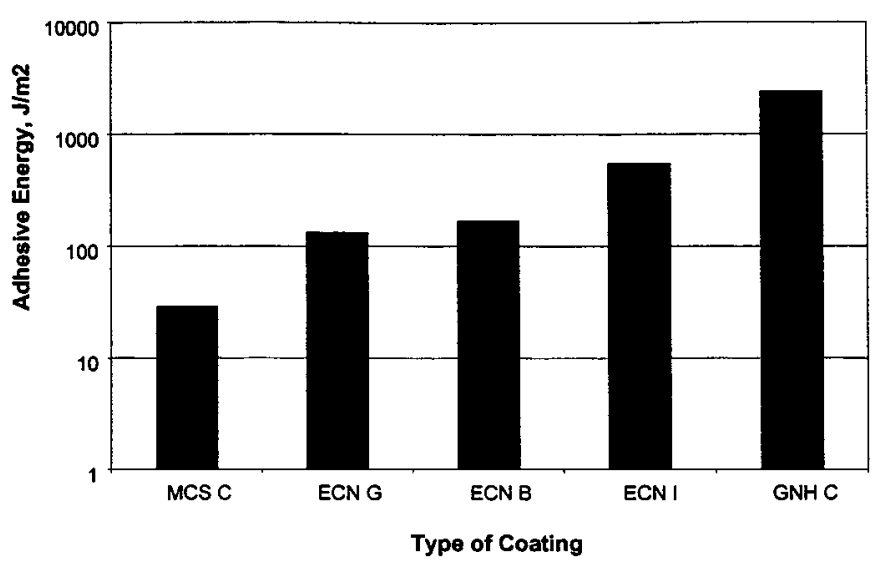

FIGURE 6

Hesiometer adhesion test results from various coatings. 


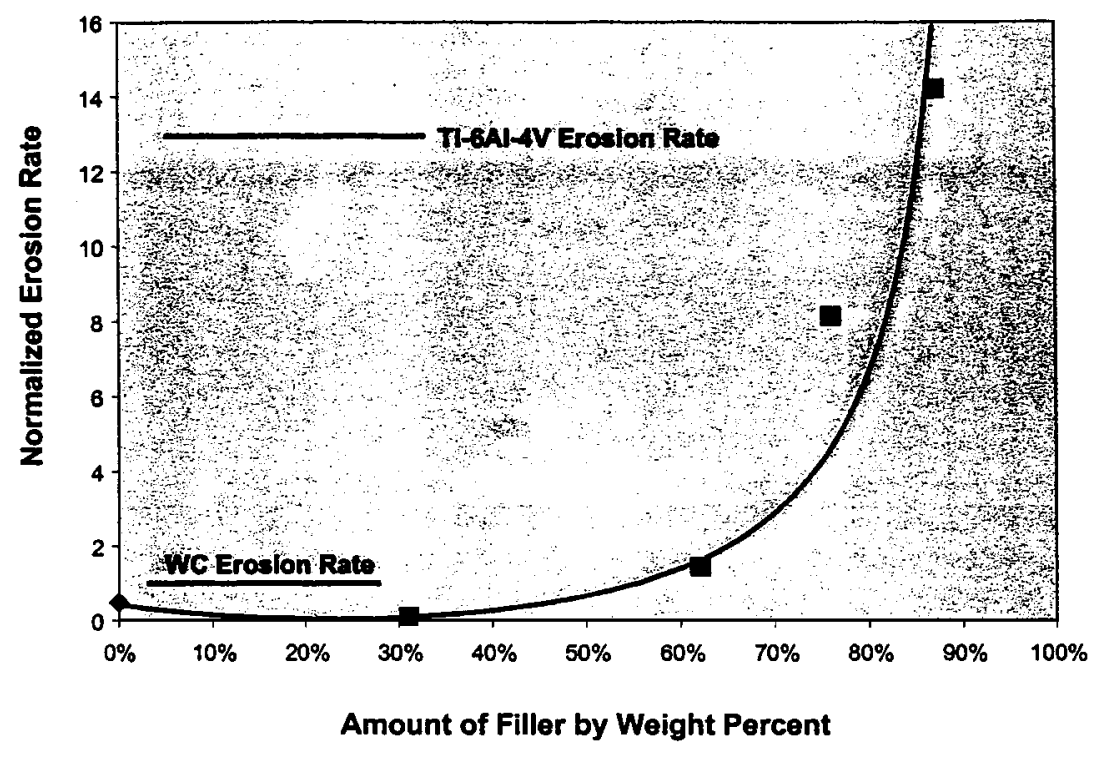

FIGURE 7

Effect of filler on erosion of ECN-A coatings.

plasma sprayed coating. Generally, matrix materials affected the erosion rate more than did the type of the ceramic filler, and the glancing-angle erosion rate was greater than for normal incidence. The more resilient matrix coatings produced the lowest erosion rates.

Figure 7 shows erosion rates (normalized to the (WC) erosion rate) for the ECN-A coating, which is based on a resilient polymer. Good erosion rates were obtained for filler levels up to $\sim 40 \%$. Also shown are data for the bare substrate and for WC erosion rates. Other batches from the ECN class of coatings were also tested for erosion rates, as summarized in Figure 8. The data show that some of the coating compositions (ECN-I and $\mathrm{ECN}-\mathrm{H}$ ) can produce low erosion rates at a higher filler loading than for coating composition ECN-A. Another promising coating class, MCS with resilient matrix, was investigated.

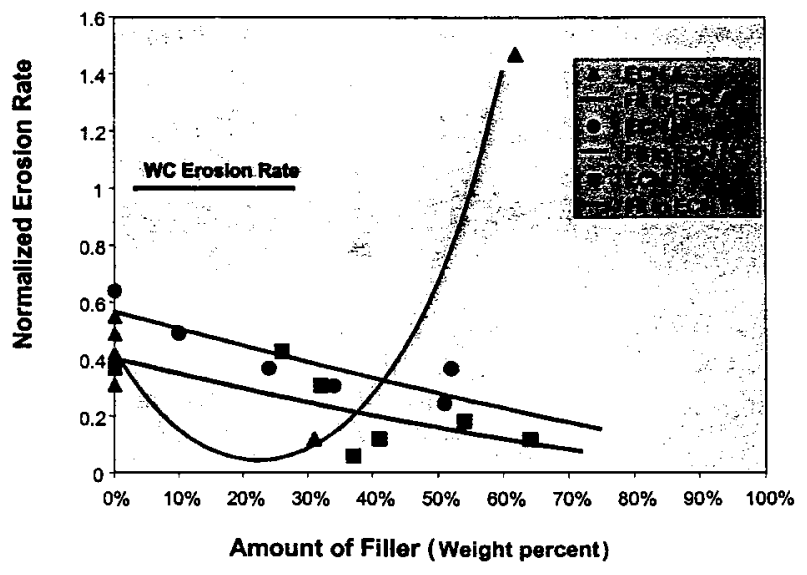

FIGURE 8

Effect of improved filler-to-matrix interface in ECN-H and ECN-I coatings on the erosion rate.
The results are summarized in Figure 9, and they show very low erosion rates, even lower rates than those of the WC coating. Another coating class, GNY, showed results between those of the ECN and MCS coatings.

Table 4 gives a summary of the erosion rates for each of the coatings, based on the erosion tests performed at UC. Although the actual erosion rate may depend on the test conditions and the particular history of the sample, it is apparent that in general, multilayered $\mathrm{Si}_{\mathrm{x}} \mathrm{C}_{\mathrm{y}} / \mathrm{DLC}$ coatings showed the lowest erosion rates, followed by those of polymer-ceramic coatings. The coatings of WC-TaC-Co and WC-TiC-Co showed the highest erosion rates of the three coatings investigated.

\section{CONCLUSIONS}

Three types of coatings were evaluated for high-velocity sand erosion behavior in a U.S. Navy Phase I SBIR program:

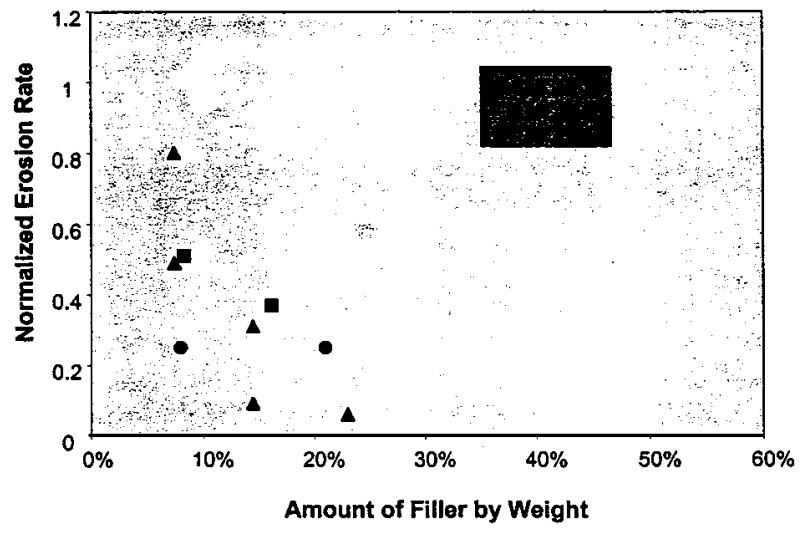

FIGURE 9

Effect of filler on the erosion behavior of MCS coatings. 
TABLE 4

A Summary of Erosion Rates of Three Types of Coatings

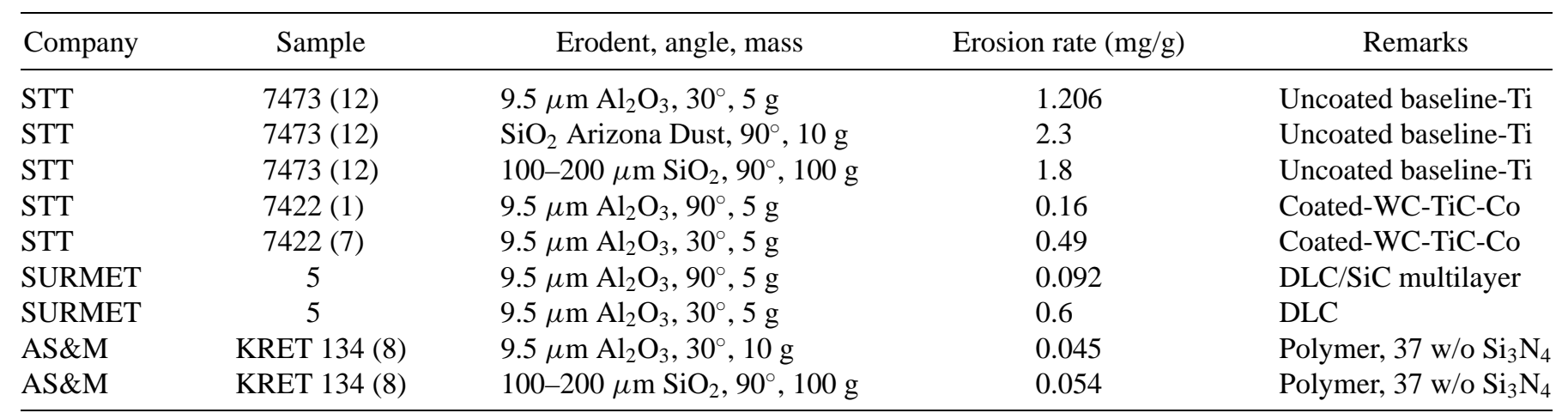

AS\&M, —; KRET 134,—; STT, Surface Treatment Technologies; SURMET,—; Ti, titanium.

multilayered $\mathrm{Si}_{\mathrm{x}} \mathrm{C}_{\mathrm{y}} / \mathrm{DLC}$ deposited by CVD; WC-TaC-Co and WC-TiC-Co processed by electrospark alloying; and polymerceramic composites synthesized by means of a liquid coating method. Each of these coatings was deposited on Ti-based substrates and erosion tested in a wind-tunnel facility at the University of Cincinnati. The preliminary results showed superior per- formance by the multilayered $\mathrm{Si}_{\mathrm{x}} \mathrm{C}_{\mathrm{y}} / \mathrm{DLC}$ and polymer-ceramic coatings in comparison to the coatings deposited by means of the electrospark alloying method.

\section{REFERENCE}

Tabakoff, W. 1995. Journal of Wear 224:186-187. 

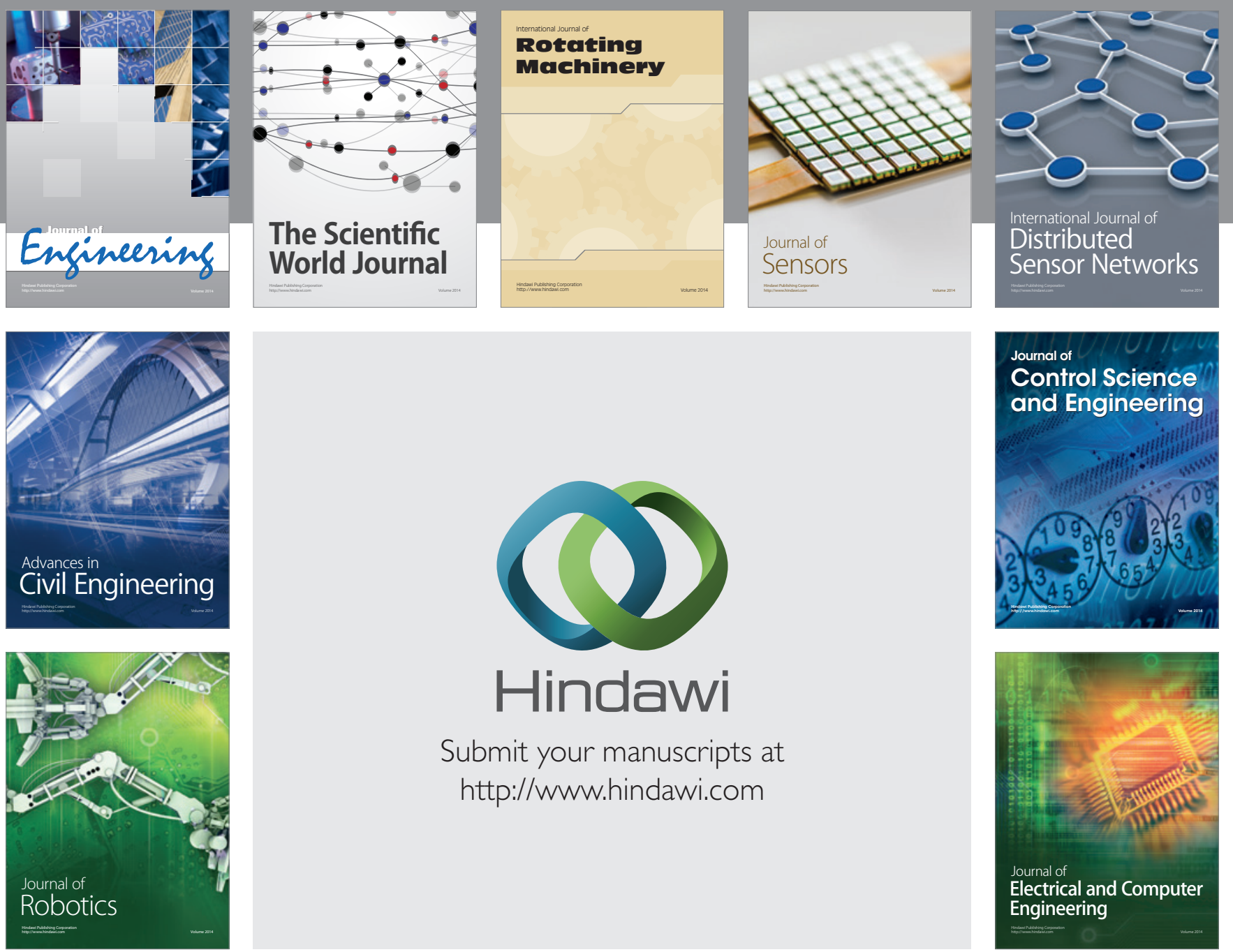

Submit your manuscripts at

http://www.hindawi.com
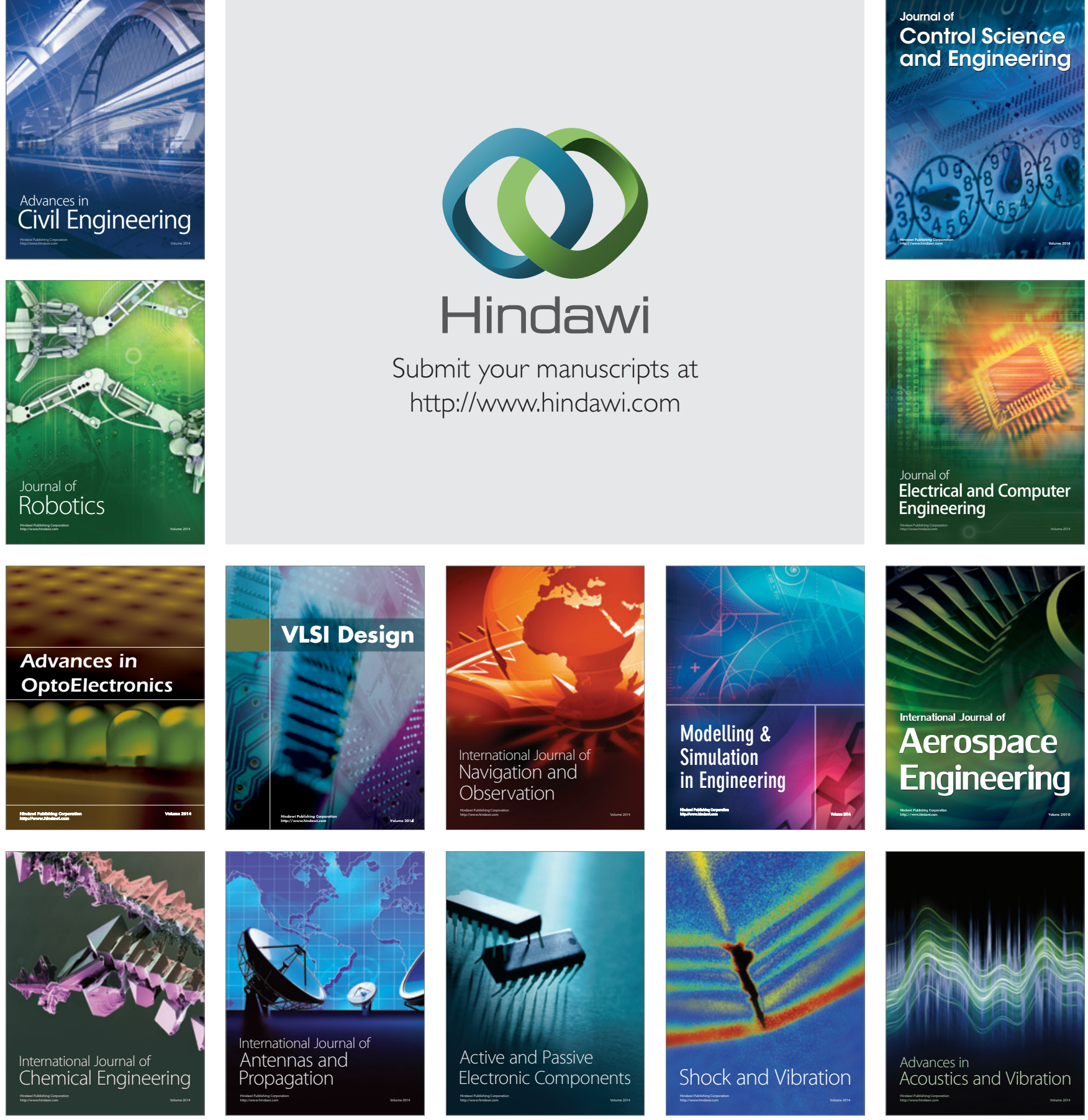